\title{
"THE GREATEST STORY EVER TOLD". SEMIOSIS EMERGING FROM MIMESIS AND/OR NARRATIVITY
}

\author{
GÖRAN SONESSON ${ }^{* 1}$, \\ *Corresponding author: goran.sonesson@semiotik.lu.se \\ ${ }^{1}$ Cognitive Semiotics, SOL, Lund University, Lund, Sweden
}

\begin{abstract}
Language may emerge as one of several specializations out of mimesis, understood as whole-body communication. Starting out from the idea of a mimetic stage as the precursor to language as first posited by Donald, and building on the observations on this notion made by Zlatev and Sonesson, we consider two recent proposals for rendering mimesis more specific. The first of these proposals, due to Żywiczyński, \& Wacewicz, aims to narrow down mimesis to pantomime, of which they try to give a precise definition. While this proposal throws much light on what is involved, pantomime in this sense can, in the end, hardly be distinguished from (communicative) mimesis, given an appropriate definition. The other proposal, due to Ferretti et alia, suggests that narrative thinking is at the origin of both mimesis and language. We argue that, while narrativity builds on the specific character of human temporal cognition, the latter cannot become narrative without first being manifested by a semiotic resource.
\end{abstract}

\section{Setting the Scene}

According to the evolutionary theory propounded by Donald (1991, 2001), episodic memory, the memory for single situated happenings, is something that human beings share at least with apes. Mimetic memory, or perhaps rather the peculiarly human form of mimetic memory, is restricted to human beings and their ancestor species. Donald terms the third stage mythic, because it involves the construction of narratives, possibly used to recount myths, this capacity being, in his view, at least one of the reasons why language evolved. Perhaps this third stage could be understood to be intermediate between biological and cultural evolution, but the fourth stage, termed theoretical, by Donald, is where evolution breaks free of biology, producing pictures, writing, and theorizing. Donald (2010) places the latter semiotic resources at this stage because they are "exograms", i.e., memory records which have an existence independently of any (specific and current) subject. There are excellent reasons to think that narrativity predates language, at least in a rudimentary form, being manifested 
both in gesture and in (not endurable forms of) pictures (See Sonesson (2007, 2016). Since then, there have been proposals, on the one hand, to consider pantomime (which, in Donald's scheme, is only one of the manifestations of the mimetic stage) to be at the origin of the process leading to the emergence of language (Żywiczyński, \& Wacewicz, 2017; \& Sibierska 2016), and, on the other hand, to suggest that narrativity as such is at the origin of language (Ferretti, Adornetti, \& Chiera, 2017). In the next section, we will discuss the first proposition, reserving the discussion of the latter for the third section.

\section{Miming Mimesis}

Donald (1991: 170ff) lists a number of criteria, which have to be fulfilled by any item pertaining to be an instance of mimesis: intentionality (in the sense of having a purpose), generativity (in the sense of being divisible into components and recombined), communicability (which Donald goes on to explain as public availability, which is really a more limited notion), referentiality (in the sense that "the referential act must be distinguished from its referent"), potentially involving an unlimited number of objects and events, and autocuing (i.e. being volitionally controlled). All through his papers, Donald (e.g. 1991, 2001, 2010) exemplifies this stage using terms current in the vernacular, some of which are rather vague and ambiguous, such as imitation, pantomime, and gesture, and others which seem to have only partly overlapping meanings, such as tool use and skill.

Sonesson $(2007,2016)$ pointed out that bodily movements that are referential, that is, which form signs, must be distinguished from action which impinges on the material world, such as tool use and skill, even though the latter may be propagated by means of imitation. For the definition of the sign, Sonesson relies on notions formulated by Husserl and Piaget: 1) the sign contains (a least) two parts (expression and content) being as a whole relatively independent of that for which it stands (the referent); 2) these parts are differentiated, from the point of view of the subjects involved in the semiotic process, even though they may not be so objectively, i.e. in the common sense Lifeworld (except as signs forming part of that Lifeworld); there is a double asymmetry between the parts, because one part, expression, is more directly experienced than the other; and because the other part, content, is more in focus than the other. None of this applies to tool use and skill.

Zlatev $(2007,2014)$ proposed a division of the notion of bodily mimesis, distinguishing between "dyadic mimesis" which includes imitation and "triadic mimesis" which brings along communicative signs. Zlatev, Donald, and 
Sonesson (2010) together proposed that bodily mimesis, involving performances of the whole body, must have been at the origin of semiotic evolution, which seems to have made human beings into a very special kind of animal. The experiment realised by Zlatev, Wacewicz, Zywiczynski, \& van de Weijer (2017), in which action employing both sound and gesture turned out to be less efficacious in communicating specific content than gesture alone, can be taken to suggest that multiple sense modalities do not constitute an ideal point of origin, but it is still possible that human semiosis began as action tailored to the body as a whole.

Whatever the fate of their "pantomime-first" proposal, we owe to Zywiczynski, Wacewicz, \& Sibierska (2016) an attempt to define pantomime, as something more specific than Donald's mimetic stage and Zlatev's bodily mimesis. Pantomime, in their sense, is mimetic, (iconically) motivated and nonconventional, improvised, (primarily) visual, but potentially multimodal, holistic and involving the use of the whole body. In order to be a precursor to language, pantomime must also, they claim, be communicatively complex, self-sufficient and semantically advanced, in the sense of being displaced, open-ended and semantically universal. If mimesis is here taken in the sense of Donald, it would seem that this already contains some of the properties listed: open-endedness appears to correspond to the reference to unlimited domains of objects, generativity, and perhaps also semantic universality. In fact, the term generativity certainly appears to go in this sense, but as Donald defines it, it seems to be in contradiction to the holistic character postulated by our authors. Surprisingly, "motivated and non-conventional" is not part of Donald's criteria, although it is implied both by the term and the examples given. It is true, however, that some of the capacities Donald qualify as mimetic, such as tool use and skill, are not iconic, except in plausibly being acquired through imitation.

Iconicity may not be as problematic as some authorities within philosophy and semiotics have claimed (see Sonesson 1989). On the other hand, nonconventionality certainly is, if it is taken to imply "some level of universality as opposed to culture-specificity" (Zywiczynski, Wacewicz, \& Sibierska 2016, no page number). We can obviously not contradict this claim by producing any examples of pantomime, since the latter is supposed to be improvised. But some iconic signs in signed languages may well have an origin in such pantomime, without being necessarily universal. In the notorious case of the sign for "tree", ASL uses the lower arm to imitate a stem with branches (apparently caught in a hurricane), and Danish sign language employ both hands to outline the contours of the treetop and the trunk, while Chinese sign language have the hands 
outlining the trunk from the bottom to the top (See Klima \& Bellugi 1979: 21f). All these signs are motivated, although the rely on different properties of the object referred to. A more general point may be that, to the extent that praxis for everyday behaviour is different in different societies (e.g. different ways of eating, sitting, greeting, and perhaps even perceiving the world, etc.), the corresponding iconical rendering will be different. ${ }^{1}$

Pantomime certainly is improvised in the sense of being autocued, but something more is implied by the term improvisation: that the signs are all the time created anew. If it is true that there are "languageless adults in Mexico deaf, never taught sign language, living together on the fringes of society /who/ mime narratives for one another" (Boyd 2009: 130f; quoted in Ferretti, Adornetti, \& Chiera, 2017), it seems probable that in such a context pantomime will rapidly be standardized, and indeed give birth to a signed language, making the claims of "languageless" deaf people highly suspect. Indeed, turn-taking, said by Żywiczyński, \& Wacewicz (2017) to be instrumental in turning pantomime into verbal language, would rather rapidly erode the spontaneity of such an improvisation. In fact, the idea of pantomime being improvised conveys up images of the occasional meetings of Neanderthals and Homo sapiens, likened by Fagan (2011: 16ff) to the meeting between the TV team led by David Attenborough and the San people, although Fagan only allows for "smiles and eyebrows that could frown, signify wonder or disapproval, or ask a question".

Another problematic criterion is that of whole-body involvement, which may extend to the environment (see Żywiczyński, Wacewicz, \& Sibierska, 2016). As the authors admit, however, "movements of the hand and arm do have a rather critical part to play in pantomime, but only to the extent that they are implicated in the holistic generation of meaning" - or, as they also frame it, as being part of a system (Żywiczyński, \& Wacewicz 2017). If we understand the term system here in the structuralist sense, it can clearly not involve the paradigmatic axis, since pantomime is supposedly improvised, but it would have to take place on the syntagmatic axis. Whatever the syntagmatic connection amounts to, nevertheless, it cannot be syntax. That leaves us wondering what kind of connection it is.

More could be said about, for instance, the problematic criterial nature of holism, but, for the time being, let us only salute the inclusion of the criterion of displacement, well-known from Hockett's design features of language, and more

\footnotetext{
${ }^{1}$ If the term sconventionality is here only meant to suggest that there are right and wrong ways of realising the pantomimic sign, then normativity may be a more adequate term.
} 
generally, from Piaget's notion of cognition. This means that pantomime will not include "interactions between chimpanzees and zoo visitors" in which "the two species imitated each other" about $10 \%$ of the time (see Persson, Sauciuc, Alenkær Madsen, 2017). Still, in the end it seems that Żywiczyński, Wacewicz, \& Sibierska (2016) have only succeeded in "unpacking", as they themselves put it, the notion of mimesis, at the price of making it more vulnerable to criticism which, in the game played by scientists, is not a small contribution. Perhaps, in the end, we should retain the term pantomime for that which is mimesis not only in the sense of Donald and Zlatev, but in the sense of the ancient Greeks (See Sörbom 1966). Aristotle, for instance, would claim, according to Ranta (2000: 68) that

" $\mathrm{X}$ is a mimetic object if $\mathrm{X}$ represents, and is (to some extent) similar to (mentally imagined) types of perceivable or imagined objects, subjects, or actions."

To the extent that this definition is applied to all kinds of art, not just plastic art, it must involve some very abstract kind of similarity indeed. In this sense, Auerbach (1946) was not wrong in using the term mimesis to describe literary realism. With reference to Auerbach, however, Donald (1991: 170) points out that Auerbach's subject is not "purely mimetic".

Another question is what might bring us from pantomime to language. As we suggested above, the introduction of turn-taking must have occurred rather rapidly, and cannot be sufficient to account for the passage from mimesis to language. Another factor, mentioned by Żywiczyński, \& Wacewicz (2017) is the "platform of trust". This is certainly an excellent gauge for spelling out the difference between human beings and other animals: many experiments with primates have shown that apes, contrary to human children, do not understand the use of pointing and other semiotic vehicles, probably because they cannot imagine that anybody would help them find the food they desire (e.g. Zlatev et al. 2013 and literature referred to there). Nevertheless, it would seem that trust is a much more general factor distinguishing human beings from animals (although some trust must certainly exist among all animals living in groups). Indeed, trust was used to define the nature of society by Garfinkel (1963), the founder of ethnomethodology, who took his inspiration from the phenomenologists Schütz and Gurwitsch. ${ }^{2}$

\footnotetext{
${ }^{2}$ From a Darwinean point of view, it seems that only group selection can account for the survival value of trust, whether or not you postulate a cheater module. Thus, it would define Ego-culture, in the sense of Sonesson $(2012 ; 2016 a, b)$. But that is not our present concern.
} 


\section{Manually Retelling the Tale}

Perhaps narrativity, then, is the key to the passage from mimesis to language. It happens to be the other part of the definition of art (which we must take as equivalent to semiotic resources) propounded, in different ways, by Plato and Aristotle, i.e. diegesis (See Sörbom 1966). After all, from Lessing to Donald, all authorities have claimed that only language can tell a story, or at least that language does it best. Lessing, who is more explicit about his argument, says that language, since it consists of signs in time, is better at rendering temporal facts, while pictures, which are signs in space, may have an advantage as far as rendering spatial facts is concerned. There are problems with this description, which do not have to concern us here (see Sonesson 1997; 2014). Mimesis, gesture, pantomime, and anything of the kind are immune to this critique, if it is at all relevant, because, to the extent that they are signs, they certainly are temporal at the level of expression, which is what counts here.

According to Ferretti et alia (2016a, b; cf. Ferretti \& Adornetti 2016), narrativity is not only manifested already in mimesis, but, before that, there is narrative thinking. A lot could be said about this claim relative to the criteria distinguishing narrativity and narrativehood, as characterized by Prince, Ryan, and others (see Sonesson 1997 and below), but, at present we are concerned with a much more fundamental distinction. Most narratologists take it for granted that a narrative is built up from some kind of semiotic resource, normally language, which represents some other level of reality, however fictive. In the so-called Paris school, inspired by the work of Greimas, narrativity, nevertheless, is applied also to events taking place in the real world of our experience. Curiously, the abundant use of the term "representation" in cognitive science seems to lead to the same confusion.

If we follow classical narratology in defining narrative, not as a sequence of events, but as an "external" representation of such a sequence, we still have to face the rejoinder that the single subject may be telling himself a tale. The question is what this means. As observed by Sonesson (2015), animals like the tick only need to be aware of reality in terms of before and after (McTaggart's B-series). Mammals generally, and at least some birds, clearly live in a world in which time is counted in terms of past, present and future (McTaggart's Aseries), which requires the insertion of the ego into the stream of consciousness. Moreover, some animals are able to distance themselves from the streaming of the stream of consciousness, initiating themselves (i.e. autocuing) the acts of remembrance and anticipation, or, in other terms, "mental time travel". Indeed, Ferretti et alia $(2016 \mathrm{a}, \mathrm{b})$ refer to "mental time travel", to justify the idea of 
narrative thinking preceding any other manifestation of narrativity.

While the ability to accomplish acts of remembrance and anticipation certainly requires an advanced ability to distance oneself from one's own stream of consciousness (once one possesses one), a further level of distancing would probably be required in order to collegiate the acts of remembrance and anticipation in the form of a narrative sequence, that is, to form a minimal story, as defined by Prince (1982: 1): "at least two events with a temporal link on the content side" - which, as observed by Sonesson (1997), presupposes there to be an expression side, which does not, however, necessarily have a temporal link. The idea of a temporal link could be explicated in the following way: given two state descriptions which pertain in some sense to the same piece of the world, the temporal moment described in one of them is different from that in the other. If there is such a link in mimesis, however, it would necessarily have to be parallel in expression and content, while this is (pace Lessing) rarely the case in language (See Sonesson 2014). Thus, language is able to externalize the mental acts of remembrance and anticipation, in the shape of flashbacks and flashforwards. Donald's claim that narrative is wedded to language in the mythic stage can be understood in the sense that each stage is characterized by the properties it brings to full fruition. On the other hand, myths may not be prominent for containing flashbacks and flash-forwards - although they are endemic already in Homer.

Sonesson (1997) has argued that some of the criteria which, according to Prince (1996), bring us from mere narrativehood to narrativity, can be realised by static pictures, while others cannot. It may be difficult for a single picture to show logically unpredictable antecedents or consequences; deep causality (first and last events linked in significant ways); elements of conflict between different subjects; etc. Pantomime would seem to be closer to language in these respects. Like language and pictures, pantomime may be able to illustrate transactiveness (actions as opposed to happenings) and transitiveness (events involving agent and patient). However, because of its rough way of creating similarity, it may be worse off than pictures for rendering specificity instead of generality (the opposite of sequences fitting any or indefinitely many sets of circumstances) and the presence of virtual actions (what could have happened but did not - alternative courses of action). ${ }^{3}$

It is, of course, also possible for cognition to fulfil these criteria. But if the result of these cognitions remains in thought only, there is no expression

\footnotetext{
${ }^{3}$ Experimental evidence would need to be adduced to enrich our understanding of these issues.
} 
corresponding to this content. Such a claim, naturally, will have to rely on Husserl's (1980) argument, taken up again with empirical references, by Thomson (2007), that mental images are not really images, but reactivations of the corresponding actions.

\section{Conclusion}

As a preliminary conclusion, it might be better to think of language and all other kinds of semiosis emerging from mimesis in the general sense of whole-body communication (Zlatev, Donald, and Sonesson 2010). In this sense, mimesis contains the embryo not only of pantomime, language, and narrativity, but also of depiction, each of which eventually become specialized into their own semiotic resources. In fact, when Arbib (2012: 219) says that pantomime has its limitations, because it is hard to pantomime "blue", this is hardly an argument for the development of language. You can invent a gestural emblem for blue, just as easily as you can coin a word for it, but in none of these cases will you really be able to convey the experience of blueness, if it is not known beforehand. Indeed, as Lessing already said, only depiction uses signs the expressions of which are shapes and colours in space (Sonesson 2014). One could imagine drawing emerging in evolution out of the traces left on a surface by gestures, as is the case in child development. This makes sense, since we know that, in many cultures, sand painting is almost as transient an event as gesture. Pictures as exograms, in Donald's fourth stage, is a later outgrowth of depiction. But it may very well be the first instance of this evolvement.

If so mimesis, rather than pantomime or narrativity, will really be at the origin of it all. Thus, what is from the beginning a rather undifferentiated wholebody communication later divides up according to what each semiotic resource does best: language for telling stories, depiction for showing what blue and square look like, and gesture perhaps mostly as a complement to speaking and, more exceptionally, as a substitute for it, in the shape of signed language or pantomime.

\section{Acknowledgements}

The author wants to thank Jordan Zlatev and two anonymous reviewers for comments on an earlier draft of this paper. 


\section{References}

Arbib, M. (2012). How the brain got language. Oxford University Press, Oxford.

Auerbach, E. (1946). Mimesis: dargestellte Wirklichkeit in der abendländischen Literatur. Bern: Francke.

Boyd, B. (2009). On the origin of stories: evolution, cognition, and fiction. Cambridge, Mass.: Belknap Press of Harvard University Press.

Donald, M. (1991). Origins of the modern mind: Three stages in the evolution of human culture. Cambridge, MA: Harvard University Press.

Donald, M. (2001). A mind so rare: The evolution of human consciousness. New York: Norton.

Donald, M. (2010). The exographic revolution: Neuropsychological sequelae. In L. Malafouris \& C. Renfrew (Eds.), The cognitive life of things: Recasting the boundaries of the mind (pp. 71-79). Cambridge: McDonald Institute Monographs.

Fagan, B.M. (2011). Cro-Magnon: how the Ice Age gave birth to the first modern humans. (Paperback ed.) New York: Bloomsbury Press.

Ferretti, F. \& Adornetti, I. (2016) Mindreading, Mind-travelling, and the ProtoDiscursive origins of language. In Zlatev, J., Sonesson, G., \& Konderak, P. (eds.), Meaning, Mind and Communication. Explorations in Cognitive Semiotics. Frankfurt/M.: Peter Lang.

Ferretti, F. Adornetti, I., Chiera, A., Nicchiarelli, S., Magni R., Valeri G., Marini, A. (2017a) Mental Time Travel and language evolution: a narrative account of the origins of human communication. In Language Sciences 63 (2017) 105-118

Ferretti, F., Adornetti, I. \& Chiera, A. (2017b). The Narrative Dimension Of Pantomime: An Evolutionary Perspective. Lecture given at the minisymposion "The Role of Pantomime in Cognitive-Semiotic Evolution" at Lund University, September 8, 2017.

Garfinkel, H. (1963) A Conception of, and Experiments with, "Trust" as a Condition for Stable Concerted Actions, in O.J. Harvey (ed.) Motivation and Social Interaction (pp. 187-238). New York: Ronald Press.

Husserl, E. (1980). Phantasie, Bildbewusstsein, Erinnerung. Husserliana XXIII. The Hague: Nijhoff

Klima, E.S., Bellugi, U. \& Battison Robbin (1979). The signs of language. Cambridge, Mass.: Harvard University Press.

Persson, T., Sauciuc, G., Alenkær Madsen, E. (2017). Spontaneous crossspecies imitation in interactions between chimpanzees and zoo visitors. Cross-Mark: Primates. DOI 10.1007/s10329-017-0624-9

Prince, G. (1982). Narratology: the form and functioning of narrative. Berlin: Mouton.

Prince, G. (1996). Remarks on Narrativity in C. Wahlin, (ed.) Perspectives on Narratology (pp 95-106). Frankfurt: Peter Lang. 
Ranta, M. (2000). Mimesis as the representation of types: the historical and psychological basis of an aesthetic idea. Diss. Stockholm : Univ.. Stockholm.

Sonesson, G. (1989). Pictorial concepts. Lund: Lund University Press.

Sonesson, G. (1997). Mute narratives: New issues in the study of pictorial texts. In U. B. Lagerroth, H. Lund \& E. Hedling (Eds.), Interart poetics: Essays on the interrelations of the arts and the media (pp. 243-252). Amsterdam: Rodopi.

Sonesson, G. (2007). From the meaning of embodiment to the embodiment of meaning. In T. Zimke, J. Zlatev \& R. Frank (Eds.), Body, language and mind. Vol 1: Embodiment (pp. 85-128). Berlin: Mouton.

Sonesson, G. (2012). Between homeworld and alienworld: A primer of cultural semiotics. In E. W. B. Hess-Lüttich (Ed.), Sign culture - Zeichen: Kultur Festschrift for Roland Posner (pp. 315-328). Würzburg: Königshausen \& Neumann.

Sonesson, G. (2014). Translation and Other Acts of Meaning. In Between Cognitive Semiotics and Semiotics of Culture. In Cognitive Semiotics, 7:2, 2014, 249-280.

Sonesson, G. (2015). From remembering to memory by way of culture: A study in cognitive semiotics. Southern Journal of Semiotics, 5(1), 25-52.

Sonesson, G. (2016a). Lifeworlds: The Cognitive Semiotics of Culture. In Dunér, D., \& Sonesson, G. (eds.), Human Lifeworlds: The Cognitive Semiotics of Cultural Evolution (pp. 23-62). Frankfurt/M.: Peter Lang.

Sonesson, G. (2016b). Cultural Evolution: Human History as the Continuation of Evolution by (Partially) Other Means. In Dunér, D., \& Sonesson, G. (eds.), Human Lifeworlds: The Cognitive Semiotics of Cultural Evolution (pp. 301-336). Frankfurt/M.: Peter Lang

Sörbom, G. (1966). Mimesis and art: studies in the origin and early development of an aesthetic vocabulary. Diss. Uppsala : Univ.. Stockholm.

Thompson, E. (2007). Mind in life: biology, phenomenology, and the sciences of mind. Cambridge, Mass.: Belknap Press of Harvard University Press.

Zlatev, J. (2007). Language, embodiment and mimesis. In T. Ziemke, J. Zlatev \& R. Frank (Eds.), Body, language, mind. Vol 1: Embodiment, (pp. 297338). Berlin: de Gruyter.

Zlatev, J. (2014). Bodily mimesis and the transition to speech. In M. Pina \& N. Gontier (Eds.), The evolution of social communication in primates (pp. 165178). Berlin: Springer.

Zlatev, J., Madsen, E. A., Lenninger, S., Persson, T., Sayehli, S., Sonesson, G., van de Weijer, J. (2013). Understanding communicative intentions and semiotic vehicles by children and chimpanzees. Cognitive Development, 312-329.

Zlatev, J., Donald, M., and Sonesson, G. (2010). From body to mouth (and body). In A. Smith, M. Schouwstra, B. deBoer, and K. Smith, The evolution 
of language (pp. 527-528). London: World Scientific.

Zlatev, J., Wacewicz, S., Zywiczynski, P. \& van de Weijer, J. (s2017) Multimodal-first or pantomime-first? Communicating events through pantomime with and without vocalization. Interaction Studies 18:3 (2017), 455-479.

Żywiczyński, P., Wacewicz, S., \& Sibierska, M. (2016) Defining Pantomime for Language Evolution Research. Consulted online on September 11, 2017: https://link.springer.com/article/10.1007/s11245-016-9425-9/fulltext.html

Żywiczyński, P. \& Wacewicz, S. (2017) Pantomime and language evolution. Lecture given at the minisymposion "The Role of Pantomime in CognitiveSemiotic Evolution" at Lund University, September 8, 2017. 